\title{
PROFIL KELAINAN KULIT PADA PASIEN DERMATITIS ATOPIK ANAK DAN DEWASA
}

\author{
Winawati Eka Putri, Maimunah Faizin, Khamida, Nur Ainiyah \\ Universitas Nahdlatul Ulama Surabaya \\ dr.wina@unusa.ac.id, khamida@unusa.ac.id, ainiyahannuri@unusa.ac.id
}

\begin{abstract}
Abstrak
Dermatitis atopik merupakan peradangan kulit berupa dermatitis kronis residif, disertai rasa gatal, dan dapat mengenai atau menyerang bagian tubuh tertentu. Anak-anak lebih sering terkena dermatitis atopik dan 50\% menghilang saat remaja tetapi terkadang menetap dan muncul saat dewasa, atau bahkan baru mulai muncul saat usia dewasa. Tujuan penelitian ini untuk mengetahui profil kelainan kulit pada pasien dermatitis atopik anak dan dewasa. Penelitian ini merupakan penelitian deskriptif observasional dengan desain retrospektif. Populasi penelitian ini yaitu pasien anak dan dewasa yang didiagnosis dermatitis atopik di URJ Kulit dan Kelamin RSI Jemursari Surabaya tahun 2014-2015. Variabel bebas adalah jenis kelamin, usia, lokasi terjadinya lesi, serta jenis lesi. Variabel terikat adalah dermatitis atopik. Pengumpulan data dilakukan dengan menggunakan data sekunder yang diperoleh dari rekam medis pasien.Alat ukur yang digunakan adalah lembar observasi.Hasil yang diperoleh pada penelitian ini adalah 44 orang (15 pasien anak, 29 pasien dewasa pada pasien anak didapatkan 10 tempat predileksi lesi dan total yang didapatkan yaitu 22 tempat predileksi dengan tempat predileksi lesi yang paling banyak pada kaki $(27,3 \%)$. Sedangkan pada 29 sampel pada pasien dewasa, didapatkan 22 tempat predileksi lesi dan total yang didapatkan yaitu 52 tempat predileksi dengan tempat predileksi lesi yang paling banyak adalah Lengan sebanyak 7 orang $(13,5 \%)$. Pasien Anak yang mengalami Dermatitis Atopik didapatkan hampir setengahnya tempat predileksi lesi pada kaki dan jenis lesinya macula eritema. Sedangkan pada pasien Dewasa sebagian kecil tempat predileksi lesi pada lengan dengan jenis lesi pada macula eritema. Pasien dengan dermatitis atopik diharapkan dapat menghindari faktor pencetus, menjaga kelembaban dan menghindari garukan sehingga lesi tidak menyebar semakin luas.
\end{abstract}

Kata kunci : Dermatitis atopik, Kelainan kulit, Pasien anak dan dewasa.

\begin{abstract}
Atopic dermatitis is skin inflammation in the form of residual chronic dermatitis, accompanied by itching, and can affect or attack certain body parts. Children are more often affected by atopic dermatitis and 50\% disappear during adolescence but sometimes remain and appear as adults, or even begin to emerge as adults. The purpose of this study was to determine the profile of skin abnormalities in pediatric and adult atopic dermatitis patients. This research is an observational descriptive study with a retrospective design. The samples of this study were pediatric and adult patients diagnosed with atopic dermatitis at the URJ Skin and Gender Hospital Jemursari Surabaya in 2014-2015. Data collection is done using secondary data obtained from the patient's medical record. The results obtained in this study were 44 people (15 pediatric patients, 29 adult patients in pediatric patients obtained 10 sites of lesion predilection and the total obtained was 22 predilection sites with the most predilection site for lesions (27.3\%). in 29 samples in adult patients, there were 22 predilection sites for lesions and the total obtained was 52 predilection sites with the most lesion predilection sites were 7 people $(13.5 \%)$ Child patients with Atopic Dermatitis have almost half the sites of predilection of lesions in the foot and the type of erythema macular lesions. Whereas in adult patients a small proportion of sites predilection of lesions in the arm with a type of lesion in the erythema macula
\end{abstract}

Keywords: Atopic dermatitis, skin disorders, pediatric and adult patients 


\section{PENDAHULUAN}

Dermatitis atopik (DA) merupakan masalah kesehatan masyarakat di dunia dengan prevalensi pada anak sekitar 10$20 \%$ dan pada dewasa sekitar 1-3\% (Leung et al, 2012), serta sekitar 50\% dari kasus DA muncul pada tahun pertama kehidupan (James et al, 2016). Dermatitis atopik merupakan peradangan kulit berupa dermatitis kronis residif, disertai rasa gatal, dan dapat mengenai atau menyerang bagian tubuh tertentu (Boediardja, 2016).

Prevalensi DA meningkat tiga kali lipat sejak tahun 1960 (Leung et al,2012). Peningkatan prevalensi DA kemungkinan disebabkan oleh beberapa faktor misalnya urbanisasi, polusi, dan hygiene hypothesis (Pohan, 2006). Study of Asthma and Allergies in Childhood (ISAAC) menyebutkan bahwa angka kejadian DA mencapai 20\% di negara Asia seperti Korea Selatan, Taiwan dan Jepang (Lee et al., 2010). Penelitian Yuin Chew Chan dkk, di Asia Tenggara didapatkan prevalensi DA pada orang dewasa adalah sebesar kurang lebih 20\% (Chan, et al., 2006 dalam Zulkarnain, 2009). Menurut laporan kunjungan bayi dan anak di Indonesia, DA berada pada urutan pertama (611 kasus) dari 10 penyakit kulit yang umum ditemukan pada anak (Budiastuti dkk, 2007). Berdasarkan data di URJ
Penyakit Kulit Anak RSU Dr. Soetomo didapatkan jumlah pasien DA mengalami peningkatan dari 116 pasien $(8,14 \%)$ pada tahun 2006, tahun 2007 menjadi 148 pasien $(11,05 \%)$ sedangkan tahun 2008 sebanyak 230 pasien (11,65\%) (Zulkarnain, 2009). Dermatitis atopik lebih sering terjadi pada perempuan dari pada laki-laki dengan ratio kira-kira 1.5:1 (Eichenfield et al., 2014).

Anak-anak lebih sering terkena DA dan 50\% menghilang saat remaja tetapi terkadang menetap dan muncul saat dewasa, atau bahkan baru mulai muncul saat usia dewasa (Boediardja, 2016). Lesi yang terjadi pada DA cenderung menjadi kronis disertai hiperkeratosis, erosi, krusta, hiperpigmentasi, skuama, ekskoriasi, papul serta likenifikasi (Boediardja, 2016). Lesi pada pasien anak biasanya lebih kering, tidak terlalu eksudatif, dapat berupa likenifikasi, lebih banyak papul dan sedikit skuama. Berbeda dengan pasien dewasa, lesi dapat berupa plak papular- eritematosa dengan skuama atau plak likenifikasi (Djuanda dkk, 2013). Tempat predileksi DA pada pasien anak lebih sering di fosa kubiti, fosa poplitea, fleksor pergelangan tangan, kelopak mata, dan leher, serta jarang muncul di wajah (Djuanda dkk, 2013; Boediardja, 2016). Pada pasien dewasa distribusi lesi kurang karakteristik, sedangkan tempat predileksi hampir sama dengan fase anak, namun lesi dapat meluas 
mengenai kedua telapak tangan, jari-jari, pergelangan tangan, bibir, leher bagian anterior, skalp dan puting susu.

Beberapa penelitian menyebutkan bahwa di negara berkembang 10-20\% anak menderita DA dan 60\% diantaranya menetap sampai dewasa (Boediardja, 2016). Menurut penelitian Sihaloho dkk (2015) yang dilakukan di URJ Kulit dan Kelamin RSUD DR. Soetomo Surabaya, gejala klinis DA pada anak yaitu berupa gatal, bercak merah (eritema) dan kulit yang kering.

Berdasarkan penelitian yang telah dilakukan tempat predileksi kelainan kulit DA pada pasien dewasa yaitu terletak pada daerah lipatan, kelopak mata, daerah sekitar mulut, dahi, pipi, dan daerah leher (Zeppa et al, 2011). Tempat predileksi DA pada pasien dewasa dengan dapat tersebar di daerah lipatan, ekstremitas (tangan dan kaki), siku dan lutut. Selain itu dalam penelitian Ozkaya juga didapatkan kelainan kulit DA yang terjadi pada pasien dewasa dapat berupa folikel, prurigo like papules, likenifikasi/eksudatif dan nummular (Ozkaya, 2005).

Berbagai penelitian DA telah dilakukan, dan hasilnya bergantung pada kriteria diagnosis DA yang ditetapkan pada setiap penelitian serta negara dan subyek yang diteliti. Dermatitis atopik belum terlalu banyak dibahas di Indonesia, sehingga sulit memperoleh data akurat mengenai epidemiologi, insidens, maupun prevalensi di Indonesia. Maka dari itu, penelitian ini diharapkan mampu memberikan informasi tentang profil kelainan kulit DA pada pasien anak dan dewasa dengan mengambil sampel di RSI Jemursari Surabaya sebagai objek penelitian, sehingga penelitian ini dapat memberikan wawasan mengenai kelainan kulit DA.

Penelitian ini bertujuan untuk mengetahui profil kelainan kulit pada pasien DA anak dan dewasa di URJ Kulit dan Kelamin RSI Jemursari Surabaya tahun 2014-2015.

\section{METODE}

Penelitian ini merupakan penelitian deskriptif observasional dengan desain retrospektif. Populasi penelitian ini yaitu pasien anak dan dewasa yang didiagnosis dermatitis atopik di URJ Kulit dan Kelamin RSI Jemursari Surabaya tahun 2014-2015. Penelitian ini dilakukan pada bulan januari 2016. Teknik sampling dengan teknik incidental sampling. Variabel bebas adalah jenis kelamin, usia, lokasi terjadinya lesi, serta jenis lesi. Variabel terikat adalah dermatitis atopik. Pengumpulan data dilakukan dengan menggunakan data sekunder yang diperoleh dari rekam medis pasien. Data yang sudah terkumpul dianalisa secara 
deskriptif. Alat ukur yang digunakan adalah lembar observasi

\section{HASIL PENELITIAN}

1. Karakteristik Responden berdasarkan Tempat Predileksi Lesi

Tabel 1 Karakteristik Responden berdasarkan Tempat Predileksi Lesi

\begin{tabular}{|c|c|c|c|c|}
\hline \multirow{2}{*}{ Predileksi Lesi } & \multicolumn{2}{|c|}{ Anak } & \multicolumn{2}{|c|}{ Dewasa } \\
\hline & $\mathrm{f}$ & $(\%)$ & $\mathrm{f}$ & $(\%)$ \\
\hline Paha & 1 & 4.5 & 3 & 5.8 \\
\hline Pinggul & 0 & 0 & 1 & 1.9 \\
\hline Lipatan Lutut & 0 & 0 & 2 & 3.8 \\
\hline Lengan & 2 & 9.1 & 7 & 13.7 \\
\hline Dada & 0 & 0 & 2 & 3.8 \\
\hline Leher & 1 & 4.5 & 2 & 3.8 \\
\hline Payudara & 0 & 0 & 1 & 1.9 \\
\hline Sela Jari & 0 & 0 & 1 & 1.9 \\
\hline Badan & 2 & 9.1 & 3 & 5.8 \\
\hline Perut & 0 & 0 & 1 & 1.9 \\
\hline Tangan & 4 & 18. & 4 & 7.7 \\
\hline Pergelangan & 1 & 4.5 & 1 & 1.9 \\
\hline Aerola & 0 & 0 & 1 & 1.9 \\
\hline Inguinal & 0 & 0 & 1 & 1.9 \\
\hline Wajah & 0 & 0 & 1 & 1.9 \\
\hline Kaki & 6 & 27. & 5 & 9.6 \\
\hline Aksila & 0 & 0 & 1 & 1.9 \\
\hline Lipatan siku & 1 & 4.5 & 4 & 7.7 \\
\hline Jari tangan & 3 & 13. & 3 & 5.8 \\
\hline Punggung & 0 & $\overline{0}$ & 3 & 5.8 \\
\hline Kelopak mata & 0 & 0 & 1 & 1.9 \\
\hline Tungkai & 1 & 4.5 & 4 & 7.7 \\
\hline Jumlah & 22 & 100 & 52 & 100 \\
\hline
\end{tabular}

Berdasarkan Tabel 1 dari 15 sampel pada pasien anak, didapatkan 10 tempat predileksi lesi dan total yang didapatkan yaitu 22 tempat predileksi. Tempat predileksi lesi yang paling banyak ditemukan pada pasien dermatitis atopik anak adalah kaki (27,3\%). Sedangkan pada 29 sampel pada pasien dewasa, didapatkan 22 tempat predileksi lesi dan total yang didapatkan yaitu 52 tempat predileksi. Tempat predileksi lesi yang paling banyak ditemukan pada pasien dermatitis atopik dewasa adalah Lengan sebanyak 7 orang $(13,5 \%)$. lesi yang hanya sedikit ditemukan adalah pinggul, payudara, sela jari, perut, pergelangan kaki, inguinal, wajah, kelopak mata yang masing-masing hanya ditemukan pada 1 orang saja $(4,5 \%)$. Penelitian ini merupakan penelitian deskriptif observasional dengan desain retrospektif. Sampel penelitian ini yaitu pasien anak dan dewasa yang didiagnosis dermatitis atopik di URJ Kulit dan Kelamin RSI Jemursari Surabaya tahun 2014-2015. Teknik sampling dengan teknik incidental sampling. Variabel bebas adalah jenis kelamin, usia, lokasi terjadinya lesi, serta jenis lesi. Variabel terikat adalah dermatitis atopik. Pengumpulan data dilakukan dengan menggunakan data sekunder yang diperoleh dari rekam medis pasien. Data yang sudah terkumpul dianalisa secara deskriptif.

\section{PEMBAHASAN}

Dermatitis atopik adalah peradangan kulit berupa dermatitis kronis residif, disertai rasa gatal (pruritus), kekambuhan 
(eksaserbasi) dan mengenai bagian tertentu. Dermatitis atopik dapat dibagi menjadi tiga fase, yaitu: DA infantil (terjadi pada usia 2 bulan sampai 2 tahun), DA anak (terjadi pada usia 2 tahun sampai 10 tahun), dan DA pada remaja dan dewasa. Penelitian ini dlakukan pada pasien anak umur 5 -10 tahun sebanyak 15 anak dan 29 pasien dewasa.

Pada pasien anak perempuan yang di diagnosis DA yaitu sebanyak 8 sampel $(53,3 \%)$, sedangkan pasien laki-laki sebanyak 7 sampel (7\%). Sedangkan pada pasien dewasa terdapat 19 orang $(65,5 \%)$,perempuan dan pasien laki-laki sebanyak 10 orang $(34,5 \%)$. Jenis kelamin kemungkinan tidak berperan sebagai predisposisi penyakit ini, namun beberapa penelitian menunjukkan anak laki-laki lebih banyak menderita DA.

Kulit pasien DA umumnya kering, pucat atau redup, kadar lipid di epidermis berkurang, kehilangan air melalui epidermis meningkat. Jari tangan teraba dingin. Pasien DA cenderung tipe astenik dengan intelegensia di atas rata-rata, sering merasa cemas, egois, frustasi, agresif atau merasa tertekan (Djuanda dkk, 2013; Boediardja, 2016). Gejala utama DA adalah gatal (pruritus) dimana rasa gatal yang dirasakan lebih gatal daripada jenis dermatitis lainnya. Gatal dapat hilang timbul sepanjang hari, tetapi umunya lebih hebat pada malam hari. Akibatnya pasien akan menggaruk secara terus menerus yang nantinya akan memicu kerusakan sawar kulit, sehingga timbul bermacam-macam kelainan di kulit berupa papul, likenifikasi, eritema, erosi, ekskoriasi, eksudasi, dan krusta (Djuanda, 2013).

Dermatitis atopik fase anak (usia 2-10 tahun) dapat merupakan kelanjutan fase infantil atau muncul tanpa didahului fase infantil. Tempat predileksi yang paling sering adalah fosa kubiti, fosa popliteal, pergelangan tangan, kelopak mata, wajah, sekitar leher, serta tersebar secara simetris (Boediardjo dkk, 2016). Berdasarkan hasil penelitian didapatkan tempat predileksi lesi pada pasien anak paling banyak dijumpai di kaki yaitu sebanyak 6 sampel $(27,3 \%)$. Tempat predileksi lain yang juga banyak dijumpai yaitu di tangan sebanyak 4 sampel (18,2\%), Jari tangan 3 sampel (13,6\%), Lengan dan badan masing-masing 2 sampel $(9,1 \%)$. Hasil ini tidak sesuai dengan pendapat Saeki et al (2016) yang menyatakan bahwa distribusi tempat predileksi lesi pada DA fase anak yaitu di daerah leher, area lipatan kaki maupun tangan (lipatan siku dan lipatan lutut). Tempat predileksi lesi pada DA paling banyak yaitu di fosa popliteal (lipatan lutut), fosa cubiti (lipatan siku) 
serta daerah leher (Cheok et al, 2017). Tempat predileksi lesi pada DA selain ditemukan pada ekstremitas, lesi juga dapat muncul di badan (Fölster-Holst, 2014). Ada beberapa kemungkinan yang menyebabkan ketidaksamaan tempat predileksi lesi tersebut, diantaranya dari factor pemeriksa dalam hal ini dokter, dimana cara mendeskripsikan tempat predileksi lesi antar dokter satu dengan dokter lainnya berbeda.

Tempat predileksi DA paling sering dijumpai pada pasien dewasa yaitu lengan sebanyak 7 sampel (13,5\%). Tempat predileksi yang juga banyak ditemukan adalah kaki 5 sampel $(9,6 \%)$, tangan, tungkai, lipatan siku masing-masing 4 sampel $(7,7 \%)$, paha, badan jari tangan, dan punggung 3 sampel $(5,8 \%)$. Penelitian ini sesuai dengan Ozkaya (2005) bahwa tempat predileksi DA pada pasien dewasa tersebar di daerah lengan, kaki, wajah, badan, dan daerah ekstensor seperti siku dan lutut. Tempat predileksi DA pada pasien dewasa juga dapat ditemukan di daerah punggung, dada, leher serta wajah (Saeki et al, 2016).

Berdasarkan Fölster-Holst (2014) tempat predileksi DA pada pasien dewasa didapatkan pada ekstremitas inferior. Tempat predileksi kelainan kulit DA yaitu terletak pada daerah lipatan, kelopak mata, daerah sekitar mulut, dahi, pipi, dan daerah leher (Zeppa et al, 2011). Pada DA Dewasa tempat predileksi lesi dapat meluas mengenai kedua telapak tangan, jari-jari, pergelangan tangan, bibir, leher, skalp, dan putting susu (Boediardja, 2016).

Berdasarkan hasil penelitian didapatkan jenis lesi yang paling banyak didapatkan yaitu makula eritema 8 sampel (29,6\%), diikuti ekskoriasi 4 sampel $(14,8)$, makula hiperpigmentasi dan papul eritema 3 sampel (11,1\%), skuama dan krusta masing-masing 2 sampel $(7,4 \%)$. Hal tersebut sesuai dengan penelitian yang dilakukan di URJ Kulit dan Kelamin RSUD DR. Soetomo Surabaya, gejala klinis dermatitis atopik pada anak yaitu berupa gatal, bercak merah (eritema) dan kulit yang kering (Sihaloho dkk, 2015). Berdasarkan Fölster-Holst (2014) karakteristik lesi DA pada pasien anak cenderung eksudatif berupa eritema, papul, dan ekskoriasi. Pada DA fase anak lesi berbentuk papul likenifikasi dan sedikit skuama (Djuanda dkk, 2013). Berdasarkan Lyons et al (2016) karakteristik lesi akut pada DA yaitu papul eritema, ekskoriasi, dan eksudatif, sedangkan lesi kronis yaitu berupa likenifikasi.

Berdasarkan hasil penelitian jenis lesi yang paling sering didapatkan yaitu Makula eritema sebanyak 14 sampel 
$(24,6)$, kemudian diikuti papul eritema 10 sampel (17,5\%), skuama 6 sampel $(10,5 \%)$, makula hiperpigmentasi dan likenifikasi masing-masing 5 sampel $(8,8 \%)$.

DA adalah penyakit kulit kronik yang hilang timbul dengan rasa gatal, yang paling sering terjadi selama masa bayi dan kanak-kanak. Umumnya dikaitkan dengan abnormalitas fungsi barier kulit, sensitisasi alergen dan infeksi kulit berulang. DA umumnya timbul pada tahun pertama kehidupan dan sering dikaitkan dengan riwayat keluarga yang mengalami atopi. Lesi pada pasien DA fase anak lebih kering dan tidak begitu eksudatif. Lesi juga cenderung menjadi kronis disertai hiperkeratosis, hiperpigmentasi, erosi, ekskoriasi, krusta, dan skuama (Boediardjo dkk, 2016). Jenis lesi DA pada pasien anak cenderung eksudatif berupa eritema, papul, dan ekskoriasi. Pada DA fase anak lesi berbentuk papul, likenifikasi dan sedikit skuama (Djuanda dkk, 2013). Karakteristik lesi DA pada pasien anak cenderung eksudatif berupa eritema, papul, dan ekskoriasi (FölsterHolst, 2014). Berdasarkan Lyons et al (2016) karakteristik lesi akut pada DA yaitu papul eritema, ekskoriasi, dan eksudatif, sedangkan lesi kronis yaitu berupa likenifikasi. Lesi akibat garukan dapat menjadi infeksi sekunder dan nantinya kulit akan menebal dan mengalami perubahan lainnya yang juga menyebabkan gatal, sehingga terjadi lingkaran setan "siklus gatal-garuk". Rangsangan menggaruk sering terjadi di luar kendali. Rasa gatal sering terjadi pada saat malam hari, dimana waktu untuk anak istirahat, sehingga anak sering mengalami sulit tidur yang akan menyebabkan kelelahan dan berpengaruh pada konsentrasi anak di sekolah

\section{SIMPULAN}

Pasien Anak yang mengalami Dermatitis Atopik didapatkan hampir setengahnya tempat predileksi lesi pada kaki dan jenis lesinya macula eritema. Sedangkan pada pasien Dewasa sebagian kecil tempat predileksi lesi pada lengan dengan jenis lesi pada macula eritema.

\section{REFERENSI}

Boediardja Siti A. 2016. Dermatitis Atopik: Ilmu Kulit dan Kelamin, Ed VII. Jakarta: Badan Penerbit Fakultas Kedokteran Universitas Indonesia.

Boediardja, S.A., 2006. Etiopatogenesis Beberapa Dermatitis pada Bayi dan Anak. Dalam: Djajakusumah, T.S., ed. Anti inflamasi Topikal pada Pengobatan Dermatitis Bayi dan Anak. Jakarta: Balai Penerbit FK UI, 11- 28. 
Budiastuti M., Wandita S., Sumandiono., 2007. Exclusive Breastfeeding and Risk of Atopic Dermatitis in High Risk Infant. Berkala Ilmu Kedokteran, Volume 39, No. 4, Hal. 192-98.

Cheok S., Yee F., Ma J. Y. S. 2017. Prevalence and Descriptive Epidemiology of Atopic Dermatitis and Its Impact on Quality of Life in Singapore. National University of Singapore.

Djuanda S., Sularsito Sri A. 2013. Dermatitis Atopik: Ilmu Penyakit Kulit dan Kelamin, Ed VI. Jakarta: Balai Penerbit Fakultas Kedokteran Universitas Indonesia.

Fölster-Holst R. 2014. Management of Atopic Dermatitis: are there differences between children and adults. Journal of the European Academy of Dermatology and Venerology, 28:5-8.

Hammer-Helmich L., Linneberg A., Thomsen Simon F., Glümer C. 2014. Association Between Parental Socioeconomic Position And Prevalence of Asthma, Atopic Eczema, And Hay Fever In Children. Scandinavian Journal of Public Health, 42:120-27.

James W.D., Berger T.G., Elston D.M. 2016. Atopic dermatitis, eczema, and non infectious immunodeficiencies disorder. In: Gabbedy R., Pinczewski S., editor. Andrew's disease of the skin. $12^{\text {th }}$ ed. Philadelphia: Saunders Elsevier.

Leung D.Y.M., Tharp M., Boguniewicz. 2012. Atopic Dermatitis. In: Goldsmith L.A., Katz S.I., Gilchrest B.A., Paller A.S., Leffell D.J., Wolf K., editors. Fitzpatrick's dermatology in general medicine. $8^{\text {th }}$ ed. Newyork: McGraw Hill.
Lysons Jonathan J., Milner Joshua D., Stone Kelly D. 2014. Atopic Dermatitis in Children: Clinical Features, Pathophysiology, and Treatment. Immunol Allergy Clin North Am, 35(1), p. 161-183.

Pohan S.S. 2006. Dermatitis Atopik: masalah dan penatalaksanaan. Berkala Ilmu Kesehatan Kulit dan Kelamin. 18(8):165-71.

Saeki H., Nakahara T., Tanaka A. 2016. Clinical Practice Guidelines for the Management of Atopic Dermatitis 2016. Journal of Dermatology, p. 1-29.

Sihaloho K., Indramaya D. M. 2015. Retrospective Study: Atopic Dermatitis in Childhood. Berkala Ilmu Kesehatan Kulit dan Kelamin, Volume 27, No. 3, Hal. 176-82.

Y. M. Park , S. -Y. Lee, W. K. Kim et al. 2016. Risk Factors of Atopic Dermatitis in Korean Schoolchildren: 2010 International Study of Asthma and Allergies in Childhood. Asian Pacific Journal of Allergy and Immunology, vol. 34, no. 1, p. 65-72.

Zeppa L., Bellini V., Lisi P., 2011. Atopic Dermatitis in Adults. American Contact Dermatitis Society. p.40-46.

Zulkarnain, I. 2009. Manifestasi Klinis dan Diagnosis Dermatitis Atopik. Dalam: Boediardja, S.A, ed. Dermdatitis Atopik. Jakarta: Balai Penerbit FK UI, 21- 38 . 